Research Article

\title{
Conventional Construction and 3D Printing: A Comparison Study on Material Cost in Jordan
}

\author{
Rawan Allouzi, ${ }^{1}$ Wael Al-Azhari, ${ }^{1}$ and Rabab Allouzi ${ }^{2}{ }^{2}$ \\ ${ }^{1}$ Department of Architectural Engineering, The University of Jordan, Amman, Jordan \\ ${ }^{2}$ Department of Civil Engineering, The University of Jordan, Amman, Jordan \\ Correspondence should be addressed to Rabab Allouzi; r.louzi@ju.edu.jo
}

Received 16 January 2020; Accepted 3 April 2020; Published 1 May 2020

Academic Editor: Oronzio Manca

Copyright ( 12020 Rawan Allouzi et al. This is an open access article distributed under the Creative Commons Attribution License, which permits unrestricted use, distribution, and reproduction in any medium, provided the original work is properly cited.

Three-dimensional (3D) printing is a procedure used to create 3D objects in which consecutive layers of a material are computercontrolled produced. Such objects can be constructed in any shape using digital model data. First, this paper presents a state-ofthe-art review of the advances in $3 \mathrm{D}$ printing processes of construction. Then, the architectural, economical, environmental, and structural features of 3D printing are introduced. Examples of 3D printed structures are presented, and the construction challenges facing Jordan, that encouraged this study, are stated. Finally, a precise description regarding the impact of 3D printing is provided by comparing conventional construction data of Ras Alain Multipurpose Hall in Jordan and the expected data if the same building has been built using 3D printing. The suggested model is generated using Revit software. As a result of this study, an understanding of 3D printing procedure, mechanism of action, and its impact on the future of construction and architecture through economical, structural, and environmental parameters is achieved. This leads to encourage engineers and contractors to take this subject into account for construction in Jordan.

\section{Introduction}

Three-dimensional (3D) printing is an innovation technique to construct objects using $3 \mathrm{D}$ printer fed by a digital file that describes the details of this object. It is also recognized as additive manufacturing (AM), additive fabrication, additive processes, direct digital manufacturing, rapid prototyping (RP), rapid manufacturing, layer manufacturing, and solid freeform fabrication [1]. Such printer uses materials such as plastics, concrete, sand, resins, or metals [2].

Researchers studied different types of 3D printers, materials, and construction procedures to take this technique forward to construct structural components and/or whole structure [3]. Tay et al. [4] presented the previous researches conducted in 3D printing. Eight categories of research topics, namely, printing techniques analysis, material analysis, control system, data analysis, architectural design, literature review, concept analysis, and cost benefit analysis were observed. Bos et al. [5] presented the development of additive manufacturing of concrete and described in detail the 3D concrete printing facility of the Eindhoven University of Technology. In addition, the 3D concrete printing was described in terms of geometry, conducted experimental research, and the difficulties of construction.

This paper presents a state-of-the-art review of the advances in $3 \mathrm{D}$ printing procedures. The investigation of the impact of 3D printing is applied by comparing the concrete cost of conventionally built Ras Alain Multipurpose Hall in Jordan with the cost if it was built using $3 \mathrm{D}$ printing. The suggested model is generated using Revit software.

\section{State-of-the-Art of 3D Printing of Concrete Procedure}

The first attempt to use cement-based materials by the 3D printing procedure was suggested by Joseph Pegna [6]. Presently, three 3D printing processes targeted at construction for the public use, namely, contour crafting (CC), D-shape, and concrete printing. These three processes 
succeed to manufacture components of large-scale size and are suitable for construction applications.

The three processes are the same in terms of layeredbased procedure. On the contrary, each of these procedures was developed for different applications and materials (Figure 1) [7].

2.1. Contour Crafting (CC). The contour crafting (CC) construction process was developed to change the construction from the conventional method to a layer-by-layer method (Figure 2) [9]. CC is a layered construction technology developed by Dr. Behrokh Khoshnevis to automate the construction of structures of a complete house including electrical, plumbing, drywall, and insulation [10]. CC lowers the construction cost, increases the construction speed, gives more flexibility for architectural design, and provides safe and friendly environment.

The cost of construction can be estimated based on time and energy spent by the instrument and the amount of materials used to build the structure. The total construction time can be evaluated once the structure model is converted to stereolithography (STL) file, and a tool path is identified [8].

A tool path of CC for any particular structure must express the position, direction, speed, and feeding rate of the nozzle for the total construction period (Figure 3) [11]. These data are converted into a series of machine tasks that are fed to the CC machine. Then, a path with the lowest cost related with every machine task is identified [11].

2.2. D-Shape. The D-shape process is based on the binder jetting procedure which is powder deposition that is hardened using a binder. Each layer of material is placed to the required thickness and compacted, and then, the nozzles attached to frame deposit the binder where the part is to be solid. Once the part is completed, it is cleaned from the loose powder bed [12].

2.3. Concrete Printing. Concrete printing is the extrusion of cement mortar. The process has been developed to retain $3 \mathrm{D}$ freedom, with smaller resolution compared to deposition, which allows for greater control of internal and external geometries.

\section{Automated 3D Printing Features}

3.1. Construction Features. The construction industry may have one or more of the following challenges, namely, slow productivity, poor quality, low safety, and insufficient skilled labor. Some Japanese construction companies are seeking to overcome the shortage of skilled labor by implementing automation. Accordingly, they produced either single task robots to replace simple labor activities or fully automated systems that can construct high-rise steel buildings or steelreinforced concrete buildings using prefabricated components [13]. This resulted in producing more than 89 single task construction robots and 11 full automated construction systems [14].

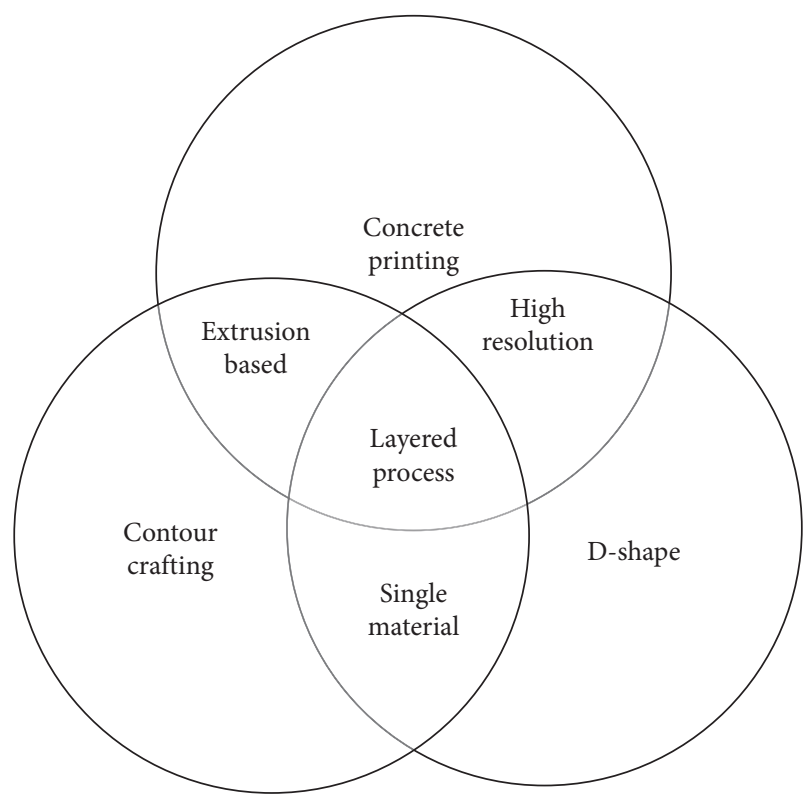

FIGURE 1: Similarities between the processes [7].

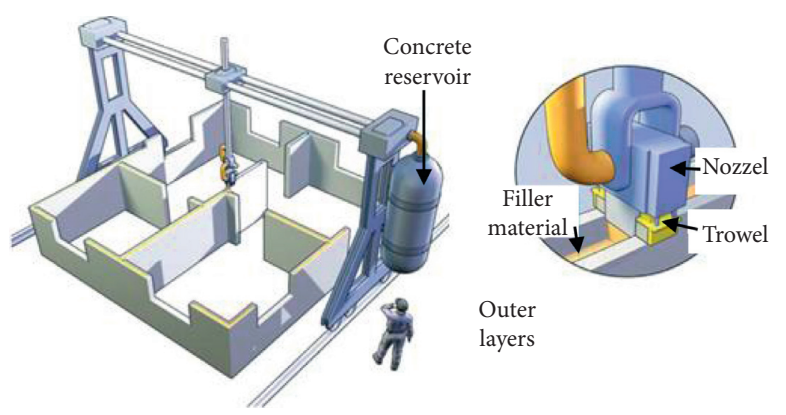

FIgURE 2: Contour crafting in construction operation [8].

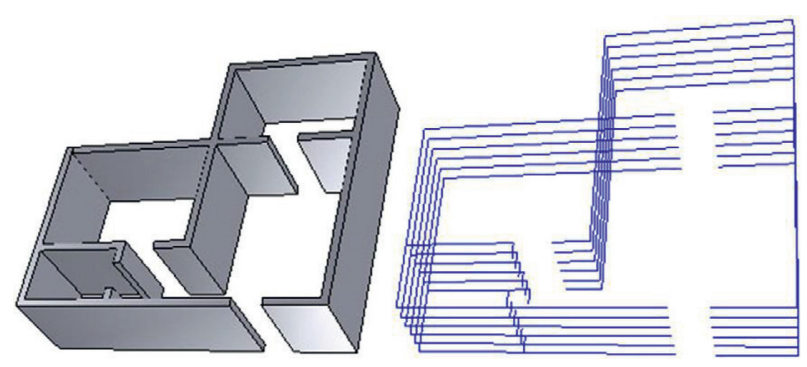

Figure 3: A structure and its CC tool path [8].

Even though the robotics have improved the productivity, safety, and quality, the construction still follows the conventional processes. Automated conventional construction like using a robot to lay bricks is expensive [13]. Therefore, the layered construction has become the new alternative in the construction industry.

For example, the installation of reinforcements and the assembly of ties and studs are labor exhausting job. Using the $\mathrm{CC}$ procedure, the installment of steel reinforcement into each layer is designed as shown in Figure 4(a) [14]. An 

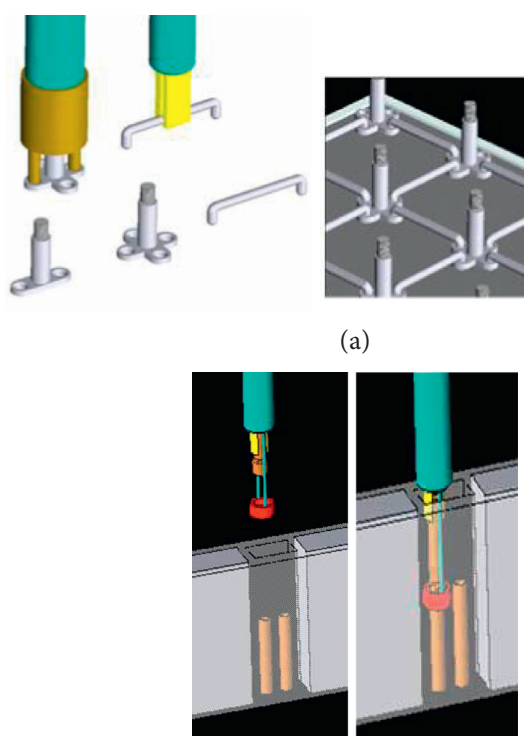

(c)

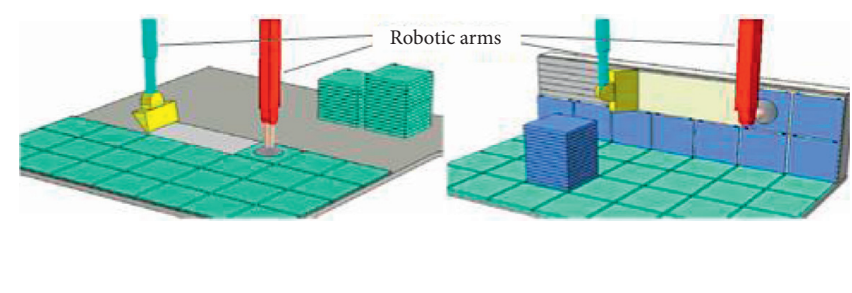

(b)

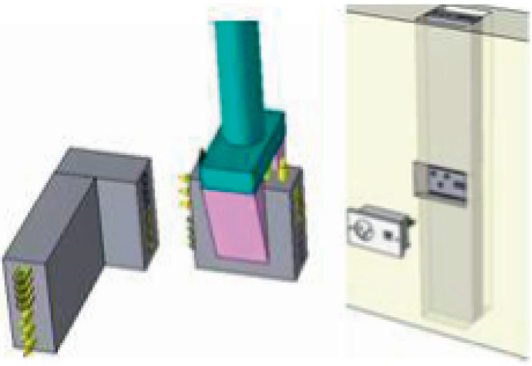

(d)

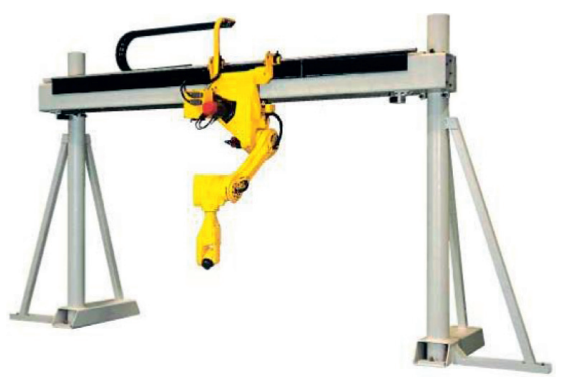

(e)

Figure 4: CC features: (a) automated reinforcement; (b) automated tiling of floors and walls; (c) automated plumping; (d) automated electrical and communication line wiring; (e) automated painting [14].

automated feeding system places three modular components and assembles them between the two edges of each layer. Concrete can then be applied [14]. The nozzle, the steel reinforcement feeder, and the concrete feeder can all be attached on the same structure.

Automated tiling of floors and walls could be integrated by robotically delivering and spreading the bonding material to floors or walls, as shown in Figure 4(b). Another robotic arm then picks the tiles from a pack and places them over the area where the bond material is placed. These robotic arms can be positioned on the same structure which moves the CC nozzle [14].

The CC method is based on layering type of construction, and accordingly, it is possible to build utility conduits within walls. This increases the potential to automate the construction of plumbing and electrical networks. For plumbing, a segment of pipe can be placed and attached through the constructed conduit (after applying several wall layers) onto the lower segment that is already installed (Figure 4(c)). The bond between the two pipe segments can be achieved by heater elements (shown in red) that melt the solder [14].

For automating electrical and communication line wiring, the modules have conductive pieces for power and communication lines inserted into nonconductive materials. A simple robotic arm can grab these pieces and connect it to the component already installed while printing the wall (same as the plumbing procedure) (Figure $4(\mathrm{~d})$ ). The fixtures are slotted through the wall openings manually [14]. During or after the placing of each layer of walls, a spray painting machine attached to the CC main structure applies paint according to the desired specifications (Figure 4(e)) [14].

3.2. Architectural Flexibility. 3D printing allows architects to design structures with various functional and bizarre geometries that are difficult to build in conventional construction practice. A schematic chart regarding the architectural flexibility relative to the cost and construction speed is shown in Figure 5.

3.3. Environmental Features. According to [16], the construction industry uses more than $40 \%$ of raw materials globally. For example, the $\mathrm{CC}$ technique can reduce the material waste from seven tons to almost none for a singlefamily home [16]. CC objects use a material as needed only. Furthermore, $\mathrm{CO}_{2}$ emission from the CC process is small fraction compared to the current emission of the conventional concrete process (CCP) of the concrete masonry unit (Figure 6). 


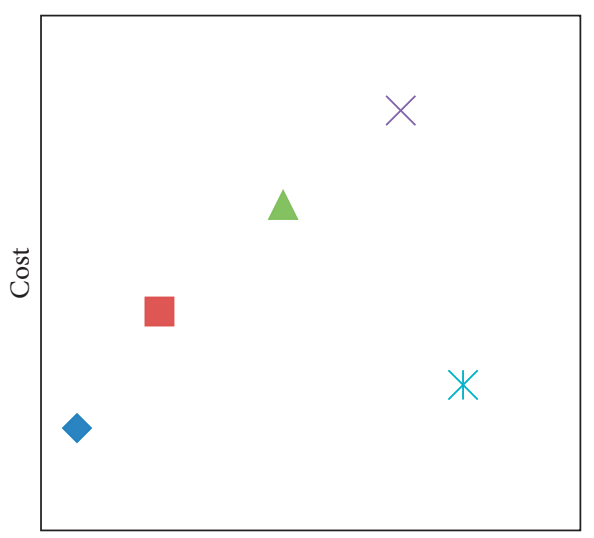

Architectural flexibility

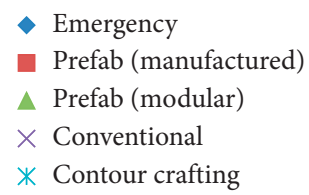

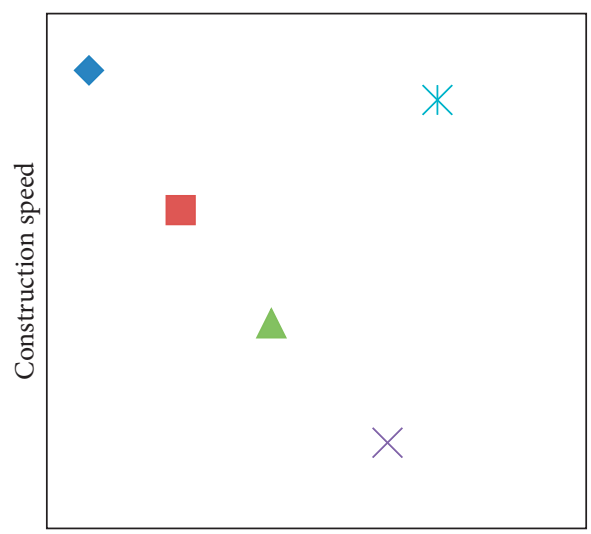

Architectural flexibility

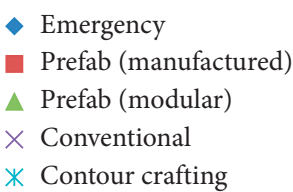

Figure 5: CC architectural flexibility in relation to its cost and construction speed [15].

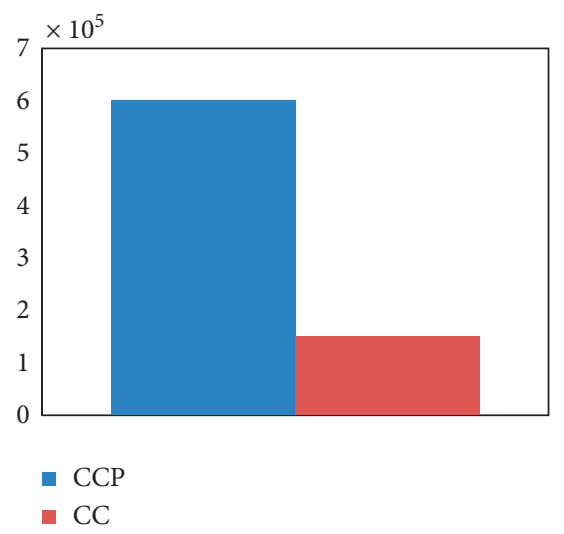

(a)

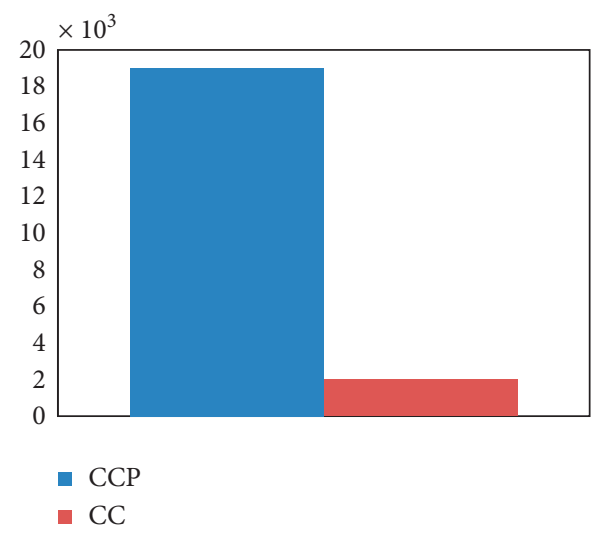

(b)

FIgURE 6: Environmental impact of CC [15]: (a) $\mathrm{CO}_{2}$ emission; (b) embodied energy.

3.4. Structural Features. Structural engineering is advancing in the building industry as a response to the development of $3 \mathrm{D}$ printing in terms of materials and structural systems as follows.

3.4.1. Advances in Materials. Traditional types of concrete are not the most convenient material for $3 \mathrm{D}$ printing as a result of predictable problems of aggregate jamming in the nozzle, compacting obstacles, and the spacing limitations due to rebar and formwork installation. Currently, more research studies are oriented to discover new concrete material or identify available concrete material to be used in $3 \mathrm{D}$ printing and have the appropriate mechanical properties and capabilities to be extruded continuously and stacked up over one another.

Many researchers printed concrete structures using several mix designs composed of cement, sand, fly ash, silica fume, and fibers [7, 17-19]. In progress research, SC3DP is investigating new printable mortars such as geopolymer mortar, lightweight mortar, and fiber-reinforced mortar for printing applications. Furthermore, recycled glass aggregates and basalt were tested to improve the construction for sustainable structures [4].

Ting et al. [20] studied using recycled glass as the fine aggregates for $3 \mathrm{D}$ concrete printing applications. The mechanical strength of concrete with sand aggregates was better compared to concrete with the recycled glass. On the contrary, the concrete with the recycled glass was more flowable than the concrete with sand aggregates. It was suggested to further study the use of concrete with sand and recycled glass for optimum mechanical and flowability properties.

Hambach and Volkmer [21] investigated the flexural and compressive strength of 3D printed fiber-reinforced mortar. Carbon, glass, and basalt fibers were studied, and improvement in flexural and compressive strength was reported. The alignment of the fibers was presented to follow the printing path to improve the material efficiency. This is 
attained during extrusion since the nozzle enables fiber to be reoriented and follows the print path.

3.4.2. Structural Integrity. In layered 3D printing, layers must be bonded together while constructing a homogeneous structure [22]. Regarding 3D printed walls, extrudable concrete must sustain the stability and structural integrity since no form work is used to stand the fresh concrete. Tay et al. [23] determined the slump and slump-flow of the printed mortar. The ability to be pumped and build was assessed based on the pumpability index and the greatest height that can be printed before collapse occurs.

Furthermore, the time between layers' placement must be planned since it is related to the strength of the layer underneath and the capability of the layers to adhere to each other [22]. The bond strength between layers identifies the structural performance of the structure. Accordingly, Zareiyan and Khoshnevis [22] performed experimental work to investigate the structural integrity of printed walls. To achieve this, the effects of the size of aggregates and the aggregate to cement ratio on the mechanical properties of the concrete were experimentally studied. Four different mixes were designed.

It was concluded that mixes with a smaller maximum aggregate size (aggregate to cement ratio is 1.15) resulted in a higher compressive strength. Shorter setting times produced cold joints at the layer interface, which resulted in less homogeneous structures. The compressive strength was higher when the height of the layers was smaller and time interval between layers' placement was shorter.

Bos et al. [24] introduced cables as reinforcement for 3D printed concrete. Pull-out test was conducted on printed concrete with different embedment lengths and various types of cables. Also, the four-point bending test was made on printed beams with cables.

The bond strength in printed concrete was very low compared to that in cast concrete. The concrete matrix exhibited flaws beneath the reinforcing cables.

The four-point bending tests showed substantial strength attained while reinforcing with B- and C-cables. Failure pattern was controlled by cable slip. This resulted in failure lower than that determined analytically. In the A-cable beams, no cable slip occurred and failure occurred close to the analytically determined amounts.

It was concluded that the concept of inserting cables as reinforcement was shown to be feasible and can achieve behavior similar to conventionally reinforced concrete. However, more research is required to improve the bond strength while reinforcing with the B- and C-cables. The A-type cable acts well but does not show enough strength for practical applications [24].

Tay et al. [25] studied the requirement of form work to support any overhanging fresh concrete. It was concluded that the nozzle speed and the rate of material flow notably affect the solidity ratio of the filament. Also, the greatest gap distance that the filament can overhang excluding a remarkable slump was investigated. An overhang structure was printed to confirm these conclusions.
3.4.3. Structural Design of Horizontal Floors. The construction of horizontal floors is challenging for 3D printing. For example, thin steel sheets can be attached to already printed beams [14]. Then, these beams (with attached sheets) can be picked and placed on the structure by robot arms (Figure 7). Finally, the 3D printer can apply the concrete on the top of the arranged beams.

ETH Zurich's Department of Architecture has designed a concrete floor slab with a thickness of $2 \mathrm{~cm} \mathrm{[26].} \mathrm{This} \mathrm{new}$ flooring system exchanges the reinforcement to thin vertical ribs, which results in considerable reduction of the weight of the system (Figure 8). Compared to traditional slabs, these floors are designed to arch to support loads. This system was inspired by the vaulted ceilings in Gothic cathedrals. The steel reinforcements are not required anymore in this case which saves the cost of these reinforcements and the time of placing them. Also, it results in using less concrete which results on $70 \%$ lighter floors than typical concrete floors [13]. A two-storey guest penthouse adopting this system will be tested at the NEST research building in Dübendorf.

3.4.4. Structural Behavior. Many structural systems, constructed using $3 \mathrm{D}$ printing procedure, were tested to better understand their behavior to judge their applicability to be adopted as a structural system. Two systems are presented herein; continuously printed walls and manual assembly of printed segments. More systems are available in industry, but their details are kept patented.

Hwang [27] tested three specimens of concrete form walls filled with concrete and one bare wall form (Figure 9). The form walls were printed and cured for 28 days. Ties were manually placed between layers, while the machine was applying the concrete wall form. A tie is inserted every $25.4 \mathrm{~mm}$ horizontally and $50.8 \mathrm{~mm}$ vertically.

Tests were conducted using a Universal Testing Machine at University of South California. All specimens were subjected to axial compressive loads till failure. The specimens were not subjected to standard capping methods which resulted in inconsistent outcomes of the compressive strength of these walls. The concrete wall made by the CC procedure was durable and was capable of retaining the fresh concrete.

The collaboration among WASP, University Federico II of Naples with the Stress Consortium, and University of Pavia resulted in constructing two reinforced beams: one straight beam and one curved beam, as shown in Figure 10 [28].

The basic idea is to print structural segment separately and then assemble these segments to create the final 3D shapes. Steel reinforcements are externally installed after the assembly is completed by anchoring the bars through the holes created while printing the segments. Rebars are intended to connect segments together and produce a single monolithic member. Accordingly, mortar can be applied to ensure proper anchoring [28].

Three-points bending test was conducted on a straight $3 \mathrm{D}$ printed reinforced concrete RC beam. Two key stages were identified based on the measured load-deflection 


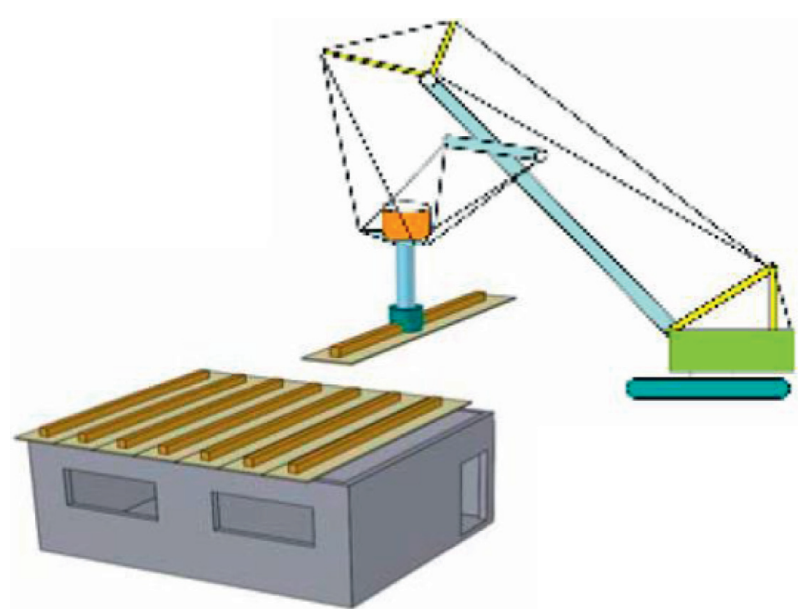

Figure 7: Horizontal floor construction [14].

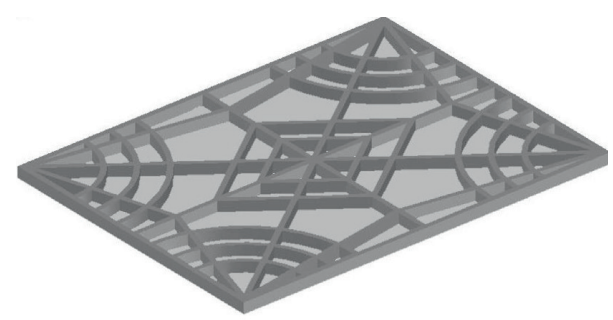

Figure 8: ETH Zurich's lightweight concrete floor slab.

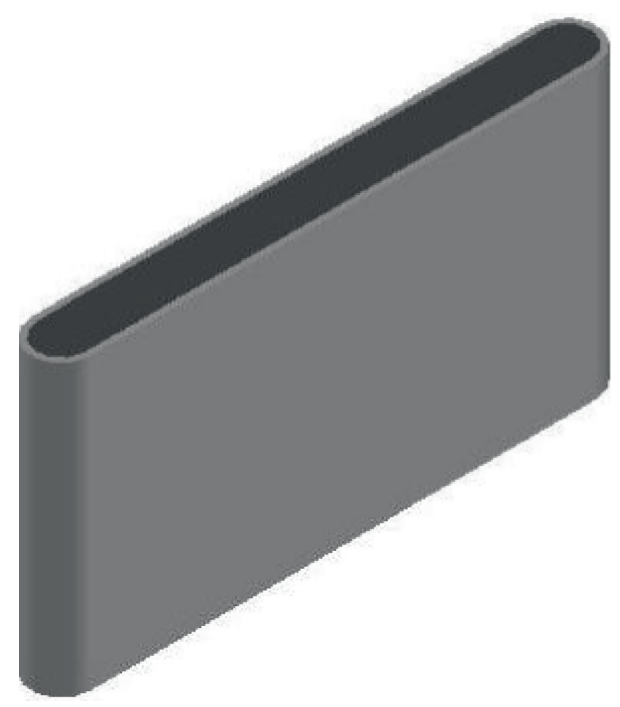

FIGURE 9: Concrete wall form constructed using CC procedure and filled with concrete.

curve: a linear elastic stage, in which the beam was not cracked nor disconnected, and a nonlinear stage, in which cracks occurred or interface failure took place. The nonlinear stage also was divided into the start of cracking stage and progression of cracking stage until the failure where complete loss of load carrying capacity of the beam took place [28].

\section{Examples of 3D Printed Structures}

4.1. China's 3D Printed Houses. In 2014, the Chinese WinSun Decoration Design Engineering Company has printed ten houses and each is approximately $100 \mathrm{~m}^{2}$ in only 24 hours. WinSun started the process with a CAD drawing imported into $3 \mathrm{D}$ printer that was used to construct the structure piece-by-piece [29]. These houses are constructed from waste material made of recycled rubble, fiberglass, steel, cement, concrete, and binder. In 2015, the WinSun printed an apartment building of six stories $\left(1,100 \mathrm{~m}^{2}\right)$ [30].

4.2. Dubai's 3D Printed Office. The 3D printed office of the future building was built in Dubai in 2016. The building used the WinSun's technology, where the walls and slabs were printed layer by layer on their side and then tilted vertically [31]. This building is single storey of $250 \mathrm{~m}^{2}$ and was designed by Gensler for the United Arab Emirates National Committee as the headquarters for the Dubai Future Foundation (DFF). The construction process took 17 days at a cost of $\$ 140,000$. A special mix of cement was used after being tested in China and the United Kingdom for reliability. The shape of arc was implemented to guarantee the stability of the office.

4.3. Saudi Arabia Future Project. In 2017, WinSun company signed an agreement with Riyadh-based Al-Mobty Contracting Company of $\$ 1.5$ billion. Under the terms of the agreement, WinSun will lease one hundred 3D printers to Al-Mobty to build 1.5 million affordable homes which equals to 30 million square meters of $3 \mathrm{D}$ printed construction area [32].

Saudi Arabia is in a serious housing crisis, and 3D printing is the suggested solution. The technology, compared to traditional construction methods, is much more costeffective, uses less material, requires less labor, and is faster.

4.4. 3D Printed Pedestrian Concrete Bridge. The first 3D printed pedestrian concrete bridge was made in the city of Alcobendas in Spain. The bridge span length is 12 meters, and the width is 1.75 meters. It is constructed from 8 separate segments that where fit together [33].

The advantages to $3 \mathrm{D}$ printed concrete including no need to molds, flexibility and adaptability to any shape, and an incredibly sturdy architectural design were observed in this project [33].

\section{3D Printing Applications and Challenges in Jordan}

In Jordan, it is essential to provide shelters for more than one million refugees taking into account the conservation of architectural heritage in Jordan. Also, the New Amman City project requires such a procedure to be involved during the city planning phase. Accordingly, this paper encourages the government and contractors to use $3 \mathrm{D}$ printing for construction. The equipment's cost depends 


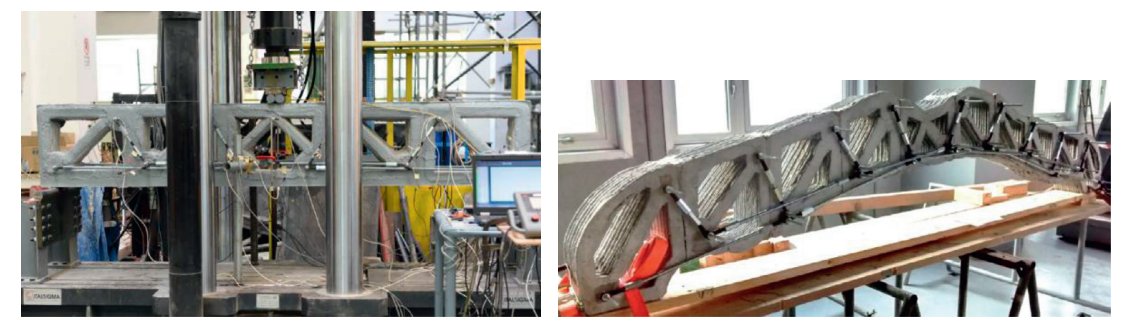

FIGURE 10: RC beams composed from printed segments connected externally with steel [28].

on the size of printer for the whole project (not only this building). BetAbram is working on two printers; $2 \times 12 \times 6 \mathrm{~m}$ that will be sold for around $\$ 27000$ and $2 \times 16 \times 9 \mathrm{~m}$ that will be sold for around $\$ 44000$. As the contractor is expected to own such a printer that will be used to print many structures, accordingly the equipment cost is considered reasonable. In addition, this cost is considered reasonable compared to the cost saving resulted from using less materials and formworks, faster construction time, and less involved labor. Better quality of construction was verified by previous researches, as mentioned previously in this paper.

All the construction works, diversity of materials, structural design guidelines, and the architectural modeling processes require further research to use it in the near future as an efficient solution for housing crisis in refugee camps and to build the new city based on high standards with low cost since Jordan is one of the developing countries that suffer from economical difficulties.

\section{Local Case Study and Simulation Process}

This section summarizes the building construction techniques and materials in Jordan and analyzes the selected case study of Ras Alain Multipurpose Hall regarding the concrete work and its cost. The mechanism of action of $3 \mathrm{D}$ printing is illustrated by applying it on Ras Alain Multipurpose Hall. At the beginning, the suggested model of Ras Alain Multipurpose Hall is generated on Revit software. Then, the model is sliced into layers by converting it to stereolithography file (STL) to create the predefined material deposition path which represents the path of the nozzle.

Also, the researchers investigated $3 \mathrm{D}$ printing and produced a precise image about the impact of $3 \mathrm{D}$ printing by comparing conventional construction data regarding design and concrete cost related to Ras Alain Multipurpose Hall with the expected data if the same building has been built using $3 \mathrm{D}$ printing.

Generally, the cost benefits of 3D printing are quantified in terms of its capability to minimize the construction time, the construction waste, the whole building embodied energy, and conventional requirements such as conventional construction tools and conventional framework. In this paper, the material cost of concrete is considered for the comparison. The saving of construction time is verified by the examples presented in Section 4 . The saving is due to the continuous work of the printer over the days with a rate of three minutes per square meter [34]. The construction time saving is not quantified in this paper since this paper focuses on the design alteration and the material cost saving.

6.1. Selected Case Study: Ras Alain Multipurpose Hall. In this section, an analytical study of Ras Alain Multipurpose Hall is undertaken in order to analyze conventional construction in Jordan. Also, architectural and structural drawings are collected from Greater Amman Municipality and analyzed in order to compare the materials' cost with the cost if the same building is built using $3 \mathrm{D}$ printing.

Ras Alain Multipurpose Hall, located in Ohud Southeast Amman, is a one-storey building with a conventional form, stone cladding, and concrete construction (Figure 11). Furthermore, it is a public building owned by the government which is the targeted group to apply $3 \mathrm{D}$ printing so that better governmental projects could be constructed with lower cost and faster time. This building has a total area of 350 square meters $\left(\mathrm{m}^{2}\right), 477 \mathrm{~m}^{2}$ exterior wall area, and 438 cubic meters $\left(\mathrm{m}^{3}\right)$ total concrete volume (Table 1). Also, it costed 240,716 Jordanian Dinar (JD) according to Greater Amman Municipality.

The building is modeled using Revit software, and each zone is represented as an individual zone according to its function, as shown in Figure 12. The perspective plan and section are presented in Figures 13 and 14, respectively.

In this section, the construction works above ground level of external walls, internal walls, and concrete works are presented first. Then, the materials' quantity and cost estimation are calculated.

6.1.1. Concrete Works. Concrete compressive strength of $20 \mathrm{MPa}$ is used for external walls behind the stone. Reinforced concrete (RC) is used for stairs and slab on grade with a concrete compressive strength of $25 \mathrm{MPa}$. A concrete strength of $30 \mathrm{MPa}$ is used for RC members of columns, slab, beam, and stairs.

6.1.2. External Walls. The external wall of Ras Alain Multipurpose Hall is a conventional wall consisting (from the inside out) of a $10 \mathrm{~cm}$ plastered hollow cement block wall, $3 \mathrm{~cm}$ of extruded polystyrene insulation, and $5 \mathrm{~cm}$ stone cladding attached to a $17 \mathrm{~cm}$ concrete layer, as shown in Figure 15. 


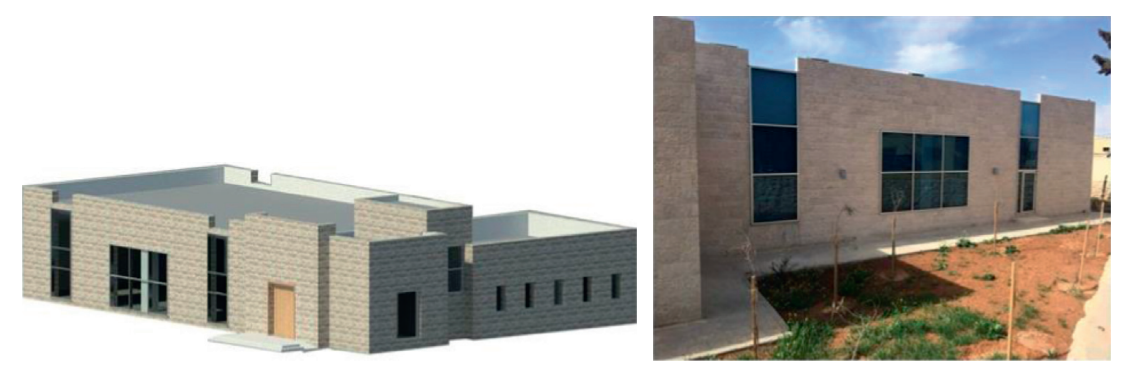

FIGURE 11: Ras Alain Multipurpose Hall exterior.

Table 1: Basic data of Ras Alain Multipurpose Hall.

\begin{tabular}{lc}
\hline Location & Ohud, Amman, Jordan \\
\hline Floor area & $350 \mathrm{~m}^{2}$ \\
Construction type & Concrete construction \\
Cladding material & Stone \\
Exterior wall area & $477 \mathrm{~m}^{2}$ \\
Total concrete volume & $438 \mathrm{~m}^{3}$ \\
Total cost & $240,716 \mathrm{JD}$ \\
\hline
\end{tabular}
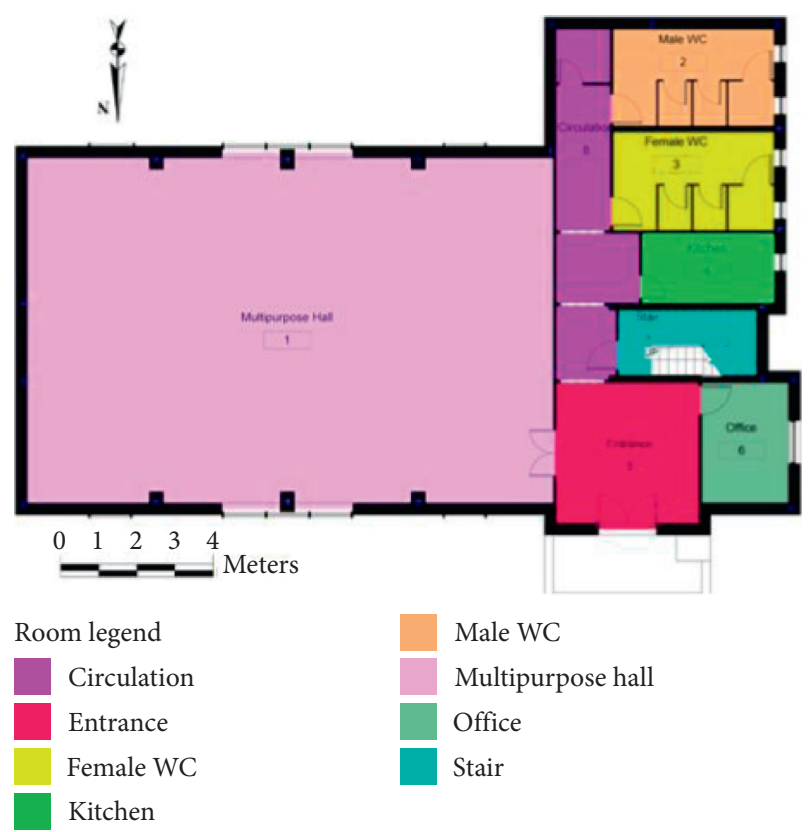

FIGURE 12: Ground floor plan with zoning Ras Alain Multipurpose Hall.

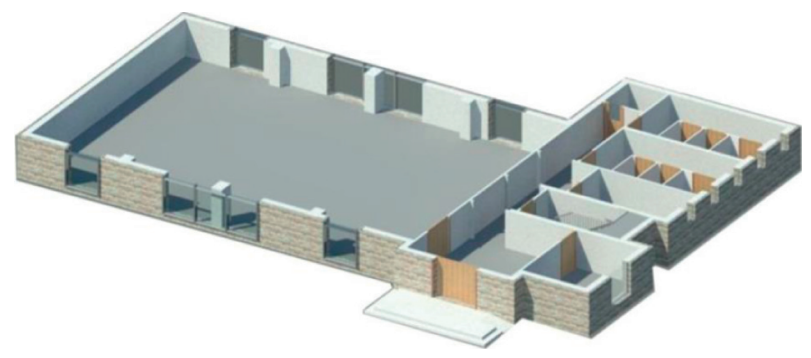

Figure 13: Perspective plan of Ras Alain Multipurpose Hall.

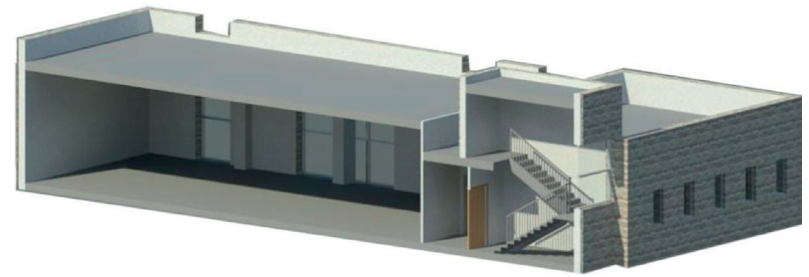

Figure 14: Perspective section of Ras Alain Multipurpose Hall.

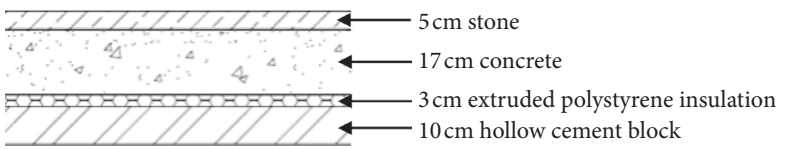

FIGURE 15: External wall of Ras Alain Multipurpose Hall (Ras Alain Multipurpose Hall drawings, 2016, adapted by author).

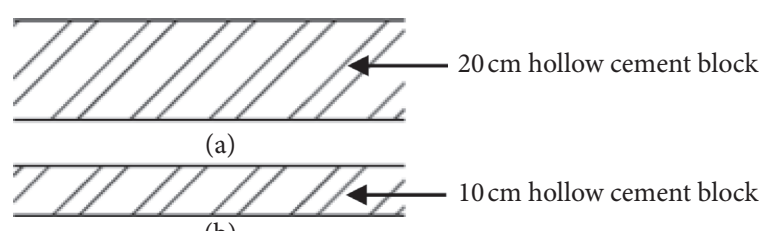

(b)

FIGURE 16: Internal walls of Ras Alain Multipurpose Hall (Ras Alain Multipurpose Hall Drawings, 2016, adapted by author).

6.1.3. Internal Walls. The internal walls of Ras Alain Multipurpose Hall are made of hollow cement block with $10 \mathrm{~cm}$ and $20 \mathrm{~cm}$ thicknesses (Figure 16).

6.1.4. Construction Problems. The construction of Ras Alain Multipurpose Hall faced several problems as follows:

(1) Falls accidents because of unprotected sides, bad scaffold construction, and not using portable ladders

(2) Although the total concrete volume is $438 \mathrm{~m}^{3}$, the contractor consumed $455 \mathrm{~m}^{3}$ of concrete so that $17 \mathrm{~m}^{3}$ of concrete is wasted

(3) The way the formwork was handled affected the quality of the concrete finish

(4) The construction completion was delayed for one week because of slow labor 
TABLE 2: Cost of construction works above ground level by conventional construction.

\begin{tabular}{|c|c|c|c|c|}
\hline Work description & Unit & Quantity & Costlunit (JD) & Total cost (JD) \\
\hline Stone attached to concrete $20 \mathrm{MPa}$ for external walls (stone height $=50 \mathrm{~cm}$ ) & $\mathrm{m}^{2}$ & 32 & 80 & 2560 \\
\hline Stone attached to concrete $20 \mathrm{MPa}$ for external walls (stone height $=25 \mathrm{~cm}$ ) & $\mathrm{m}^{2}$ & 430 & 65 & 27950 \\
\hline Extruded polystyrene $($ thickness $=3 \mathrm{~cm}$ ) for external walls & $\mathrm{m}^{2}$ & 230 & 5 & 1150 \\
\hline Hollow cement block (thickness $=10 \mathrm{~cm}$ ) for external and internal walls & $\mathrm{m}^{2}$ & 207 & 10 & 2070 \\
\hline Hollow cement block (thickness $=15 \mathrm{~cm}$ ) for external walls & $\mathrm{m}^{2}$ & 220 & 12 & 2640 \\
\hline Hollow cement block (thickness $=20 \mathrm{~cm}$ ) for internal walls & $\mathrm{m}^{2}$ & 17 & 15 & 255 \\
\hline RC $25 \mathrm{MPa}$ for stairs & $\mathrm{m}^{3}$ & 5 & 90 & 450 \\
\hline RC $25 \mathrm{MPa}$ for slab on grade (thickness $=20 \mathrm{~cm}$ ) & $\mathrm{m}^{2}$ & 216 & 17 & 3672 \\
\hline RC $25 \mathrm{MPa}$ for slab on grade (thickness $=12 \mathrm{~cm}$ ) & $\mathrm{m}^{2}$ & 225 & 12 & 2700 \\
\hline RC $30 \mathrm{MPa}$ for columns & $\mathrm{m}^{3}$ & 25 & 100 & 2500 \\
\hline RC $30 \mathrm{MPa}$ for slab and beams & $\mathrm{m}^{3}$ & 117 & 100 & 11700 \\
\hline RC $30 \mathrm{MPa}$ for stairs & $\mathrm{m}^{3}$ & 3 & 100 & 300 \\
\hline Total & & & & 57,947 \\
\hline
\end{tabular}

6.1.5. Material's Cost. This part calculates the cost of each external walls, internal walls, and concrete members. The total cost of the construction works above ground level of Ras Alain Multipurpose Hall equals 57,947 JD. The details are presented in Table 2.

6.2. Ras Alain Multipurpose Hall by 3D Printing. In this section, the building is redesigned in order to adapt the process of $3 \mathrm{D}$ printing. Construction works quantity are calculated by Revit software. The estimated cost is then compared with the calculated cost in the previous section for the same building when it was built using conventional construction.

$3 \mathrm{D}$ printing process is mainly based on the predefined material deposition path which defines the path of the printer's nozzle where the construction process and time can be evaluated once the model is converted to STL file and the tool path is defined.

The building model is first converted to STL file and sliced into layers to send the order to the $3 \mathrm{D}$ printer. The layout of one single layer is converted into a model which consists of edge and vertices. Edges represent the walls, and the vertices represent the intersections, corners, or the end points of wall segments.

In the case of Ras Alain Multipurpose Hall, the process of $3 \mathrm{D}$ printing is summarized as follows:

(1) 3D model of Ras Alain Multipurpose Hall is generated using Revit software

(2) STL exporter for Revit is installed

(3) In visibility graphics, any extra categories that will not be needed for printing such as windows and doors are turned off (Figure 17)

(4) From the Add-Ins tab in Revit, STL exporter for the Revit button is selected

(5) From the Export STL dialogue box, the STL format is set to binary and then the save button is selected to name and export the STL file

(6) Thus, the model is converted to STL file and sliced into layers (Figure 18)

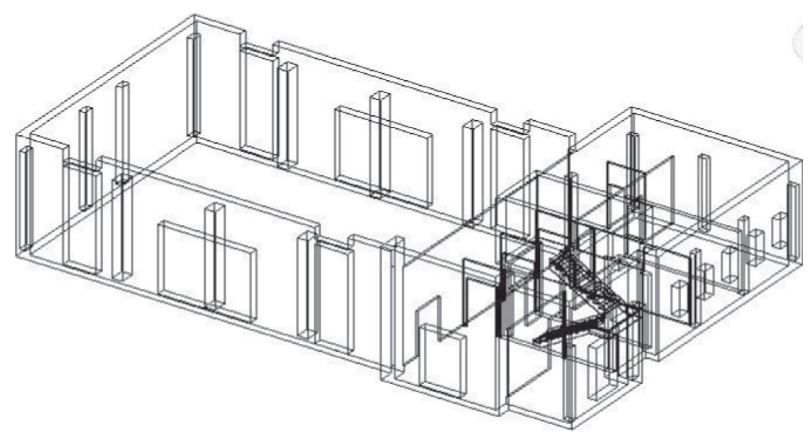

Figure 17: Categories to be printed for Ras Alain Multipurpose Hall.

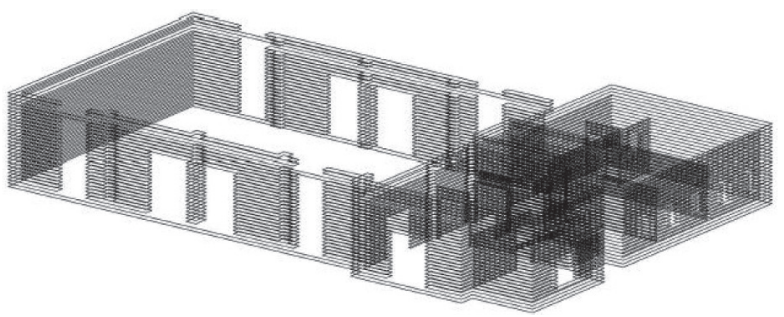

FIgURE 18: The layers of Ras Alain Multipurpose Hall.

(7) Finally, the print order should be sent to the $3 \mathrm{D}$ printer where the layers should be printed, respectively, on-site until the entire building is printed (Figure 19)

As a result, the expected on-site construction stages of Ras Alain Multipurpose Hall by 3D printing are illustrated based on Revit results, as shown in Figure 20.

This part illustrates the concrete material used and the redesign details of external walls, internal walls, lintels, and slabs in order to recognize the differences between $3 \mathrm{D}$ printing and conventional construction.

6.2.1. Concrete Material. In the case of Ras Alain Multipurpose Hall, self-compacted concrete is used to expedite concrete compaction while maintaining the quality of the structure. On the other hand, extruded self-compacted 

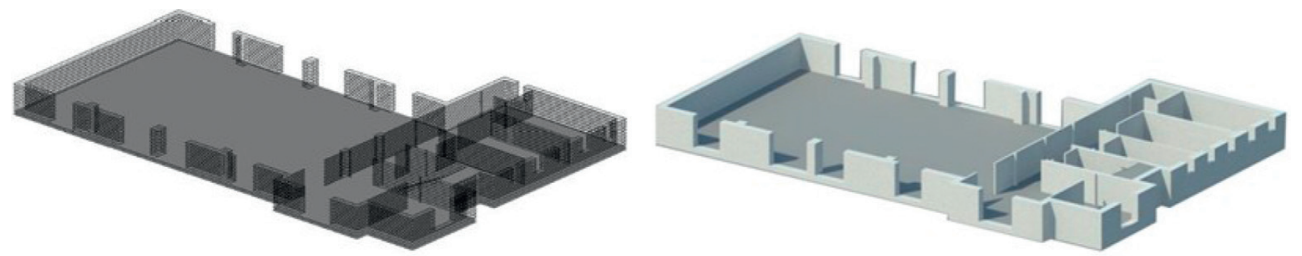

Figure 19: The printing process from STL file to the 3D printer on site.

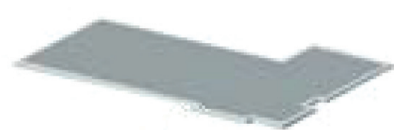

(1)

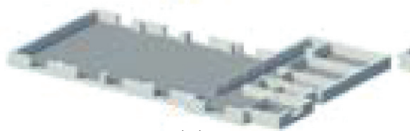

(4)

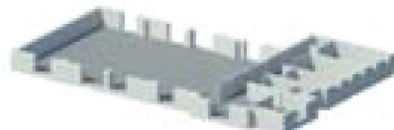

(7)

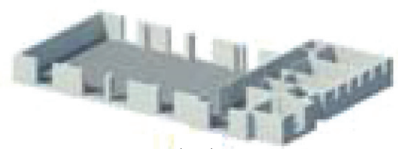

(10)

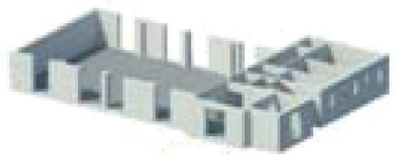

(13)

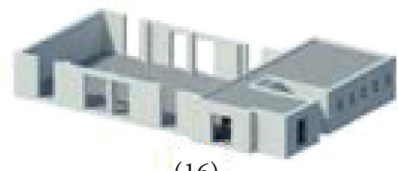

(16)

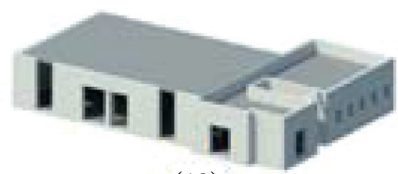

(19)

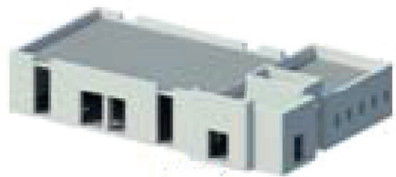

(22)

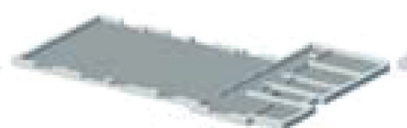

(2)

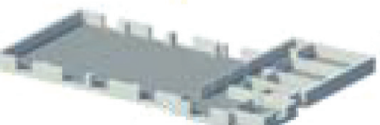

(5)

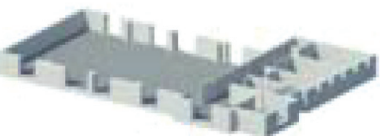

(8)

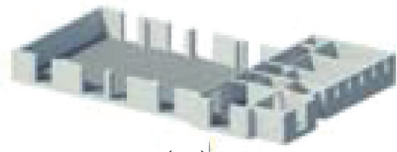

(11)

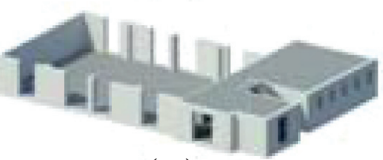

(14)

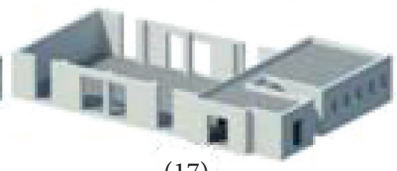

(17)

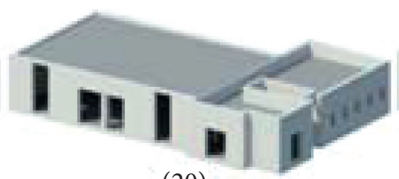

(20)

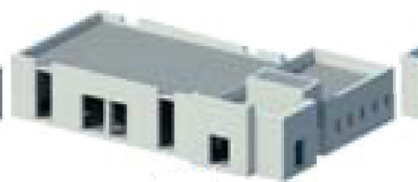

(23)

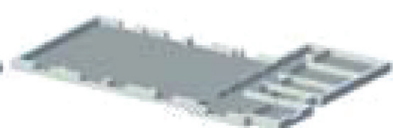

(3)

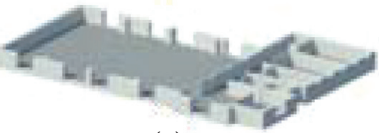

(6)

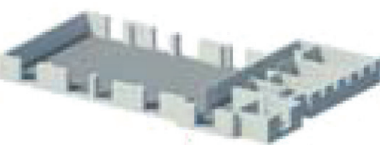

(9)

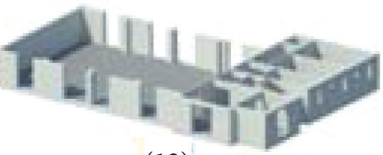

(12)

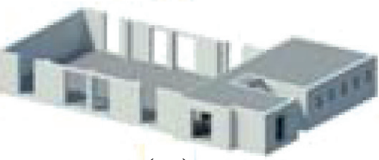

(15)

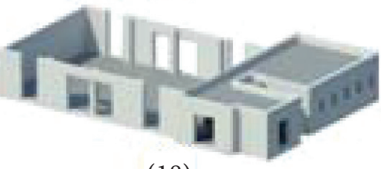

(18)

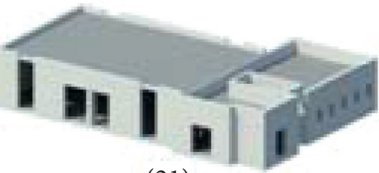

(21)

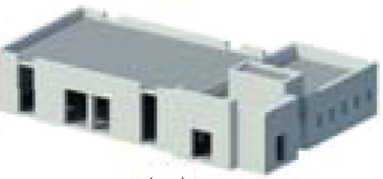

(24)

FIgURE 20: Ras Alain Multipurpose Hall construction stages by CC.

concrete addresses the formwork, aggregate, and rebar issue by using fibers that improve the cohesion of the concrete mix. Extruded self-compacted concrete is used for external walls, internal walls, slabs, beams, columns, and stairs. An array of cementitious materials could be used with different proportions of concrete or polymers where the maximum strength of a cementitious mix could reach $70 \mathrm{MPa}$ strength.

6.2.2. Frame. Steel frames are to be constructed first to support the $12 \mathrm{~m}$ span of slab level. It would be better if 
enough guidelines are available to use 3D printed beam segments connected by steel instead of steel frames. The locations of these frames are shown in the structural drawing of floor plan provided in Appendix.

6.2.3. External Wall. The external wall of Ras Alain Multipurpose Hall by 3D printing constructed without using separate formwork materials. Layers of self-compacted concrete are gradually built up to form the external hollowcore walls that are three times stronger than the external walls built with conventional concrete. In addition, these walls can still be customized to simultaneously add in plumbing and electrical fixtures and even infrastructure pipes [35]. To build the $30 \mathrm{~cm}$ thickness, the nozzle builds the outside edges with thickness of $5 \mathrm{~cm}$, then it builds $2.5 \mathrm{~cm}$ thickness of the central axes, and finally, it builds $2.5 \mathrm{~cm}$ thickness of the zigzag line in the two sides of the central axes to ensure the coherence of the wall (Figure 21). After the whole walls are constructed, it would be cladded with stone.

6.2.4. Internal Wall. The internal wall of Ras Alain Multipurpose Hall by $3 \mathrm{D}$ printing is constructed in two types: the first one is solid-core wall with $10 \mathrm{~cm}$ thickness. The second type is a hollow-core wall with $15 \mathrm{~cm}$ thickness where the extrusion nozzle builds the outside edges with thickness of $2.5 \mathrm{~cm}$, and then it builds $2.5 \mathrm{~cm}$ thickness of the zigzag line to ensure the coherence of the wall (Figure 22).

6.2.5. Lintels. The lintels are printed first and placed aside of the building until their turn to be placed above each opening. Then, robotic arms grab each lintel and place it on the right place after the required wall layers are printed. Lastly, the nozzle continues placing concrete layers between lintels and continues to place concrete above them until slab level.

6.2.6. Slabs. Thin steel sheets attached already to $3 \mathrm{D}$ printed beams are to be prepared first and placed aside of the printer. Then, these beams with attached sheets are picked by robot arms and placed on the floor level (Figure 7) such that the vertical reinforcement of walls passes through the holes at the edge of these steel sheets. Screws are then placed and rotated to tighten the steel sheets to wall reinforcements. Finally, the 3D printer can apply the concrete on the top of the arranged beams to finish the slab.

6.2.7. Material's Cost. The quantities of materials composing the above ground level of external walls, internal walls, and concrete members are calculated using Revit. The total quantity equals to $325 \mathrm{~m}^{3}$, and the cost of extruded selfcompacted concrete built by $3 \mathrm{D}$ printing per $\mathrm{m}^{3}$ is estimated to be about 27.3 JD [36]. The total cost of concrete material is presented in Table 3, which equals 8872.5 JD.

\section{Results}

Efficiency of applying 3D printing in a building in Jordan as an alternative to conventional construction is investigated

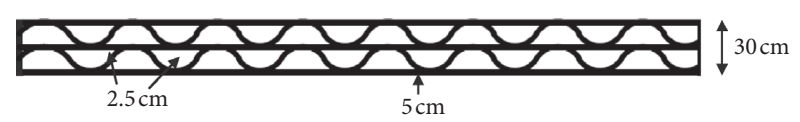

FIgure 21: External wall of Ras Alain Multipurpose Hall by CC.

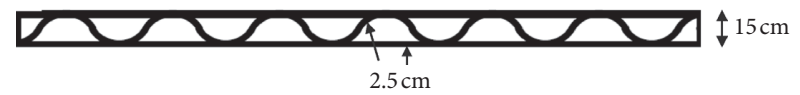

FIGURE 22: Internal walls of Ras Alain Multipurpose Hall by CC.

TABLE 3: Cost of construction works above ground level by CC.

\begin{tabular}{lcccc}
\hline Work description & Unit & Quantity & $\begin{array}{c}\text { Cost/unit } \\
\text { (JD) }\end{array}$ & $\begin{array}{c}\text { Total cost } \\
\text { (JD) }\end{array}$ \\
\hline Self-compacted concrete & $\mathrm{m}^{3}$ & 325 & 27.3 & 8872.5 \\
Total & & & & 8872.5 \\
\hline
\end{tabular}

TABLE 4: Material cost comparison between conventional construction and CC technique.

\begin{tabular}{lc}
\hline Construction type & Total cost (JD) \\
\hline Conventional construction & $26,287.0$ \\
CC technique & 8872.5 \\
\hline
\end{tabular}

based on concrete cost-related to Ras Alain Multipurpose Hall and the expected cost if the same building has been built using $3 \mathrm{D}$ printing.

The analysis shows that Ras Alain Multipurpose Hall constructed by 3D printing costs $8,872.5$ JD with the exception of the stone cladding and insulation works. On the contrary, it costs 57,947 JD by conventional construction. To compare the cost of the two construction types, conventional construction with the exception of the stone cladding and insulation works equals 57,947-2,560-2,7950$1,150=26,287 \mathrm{JD}$.

So that, for Ras Alain Multipurpose Hall, concrete cost based on 3D printing which equals $8,872.5$ JD is less than conventional construction cost which equals 26,287 JD (Table 4).

As a result, $3 \mathrm{D}$ printing reduces $65 \%$ of the conventional construction cost of material if it is applied in Jordan. The equipments' cost, construction time, and labor costs were not calculated herein since they depend on the required size and speed of printer for the project (not just this building) and the working hours during the day which are not specified in this paper.

\section{Conclusions and Recommendations}

This paper presents a state-of-the-art review of the advances in $3 \mathrm{D}$ printing construction of concrete. This research has presented an alternative construction method (3D printing) to conventional construction.

The $3 \mathrm{D}$ printing features are summarized to highlight how $3 \mathrm{D}$ printing solves problems that conventional 


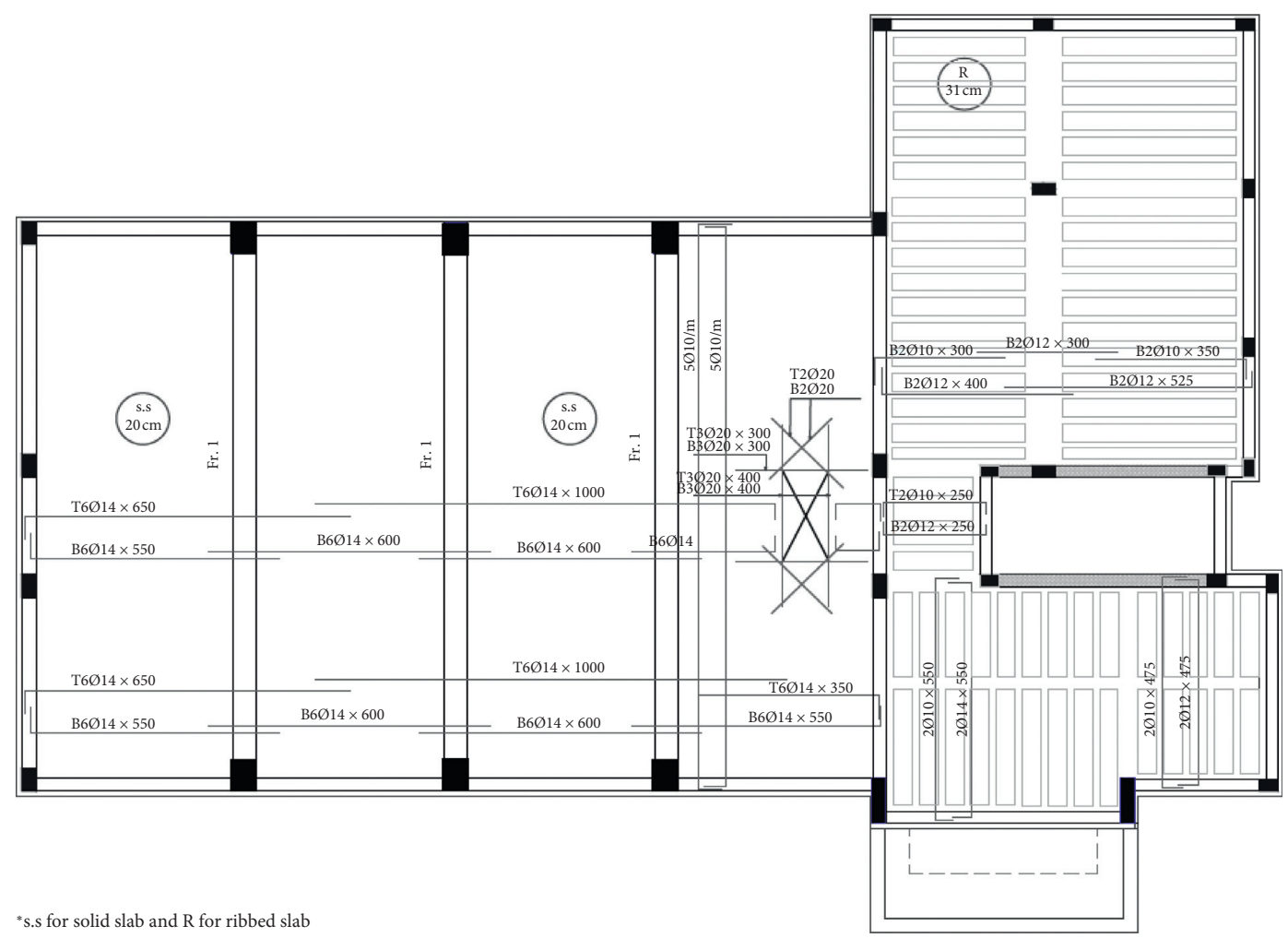

FIgURE 23: Conventional construction.

construction is facing. Economically, it is a faster and more accurate construction method for complex members and low labor costs and has zero generated waste. At a construction rate of about three minutes per square meter, a modest-sized 230 square meter $\left(\mathrm{m}^{2}\right)$ home could be constructed in about 18 or 19 hours with a workforce of about four people [34]. Architecturally, it could create more efficient and interesting designs as $3 \mathrm{D}$ printing can achieve shapes that conventional procedures cannot with architectural flexibility and high precision. Environmentally, 3D printing could be recognized as a sustainable process which reduces the consumed raw materials, the produced $\mathrm{CO}_{2}$ emission, and the consumed embodied energy.

Structurally, the material selection still advances to overcome the low tensile strength of concrete and the low bond resistance between concrete layers. Many structural systems are presented in this paper, but the authors find this field still demanding more structural testing of such systems and inquire proposing more creative structural members that are capable to overcome the drawbacks the present systems are facing.

Furthermore, four case studies of currently printed structures are presented. In China, ten houses were printed in 24 hours by a massive $3 \mathrm{D}$ printer. Each house is approximately $100 \mathrm{~m}^{2}$, and the cost of each small dwelling is less than $\$ 5,000$ because of the fast process and the low labor costs. The same company printed an apartment building of six stories. It is approximately $1,100 \mathrm{~m}^{2}$ fabricated using construction waste of concrete, fiberglass, sand, and a special hardening agent. This is considered valuable in terms of recycling materials. Accordingly, $60 \%$ of the materials are needed to construct a home with $70 \%$ of the time saving compared to conventional construction.

Dubai's Office of the Future was printed using WinSun's tilt-up technology where the floor, walls, and ceiling are all printed on their side layer by layer and then tilted vertically. The $250 \mathrm{~m}^{2}$ office is constructed and completed within 17 days at a cost of $\$ 140000$. The cost was cut by more than $50 \%$ compared to conventional buildings of similar size.

WinSun company signed an agreement to lease one hundred 3D printers to Al-Mobty to build 1.5 million homes in Saudi Arabia where a serious housing problem is being faced by their citizens.

The first 3D printed pedestrian concrete bridge was made in the city of Alcobendas in Spain. The bridge span length is 12 meters, and the width is 1.75 meters. It is constructed from 8 separate segments that were fitted together.

In Jordan, providing shelters for refugees and planning of the New Amman City project inspired this research to use $3 \mathrm{D}$ printing to save time and cost of construction besides the environmental and architectural benefits. As the contractors are expected to use 3D printer to build many structures, the equipment cost can be considered reasonable. The labour cost and the construction time are expected to be reduced based on available research studies.

The authors have summarized building construction techniques and materials in Jordan and analyzed the selected case study of Ras Alain Multipurpose Hall. The mechanism 


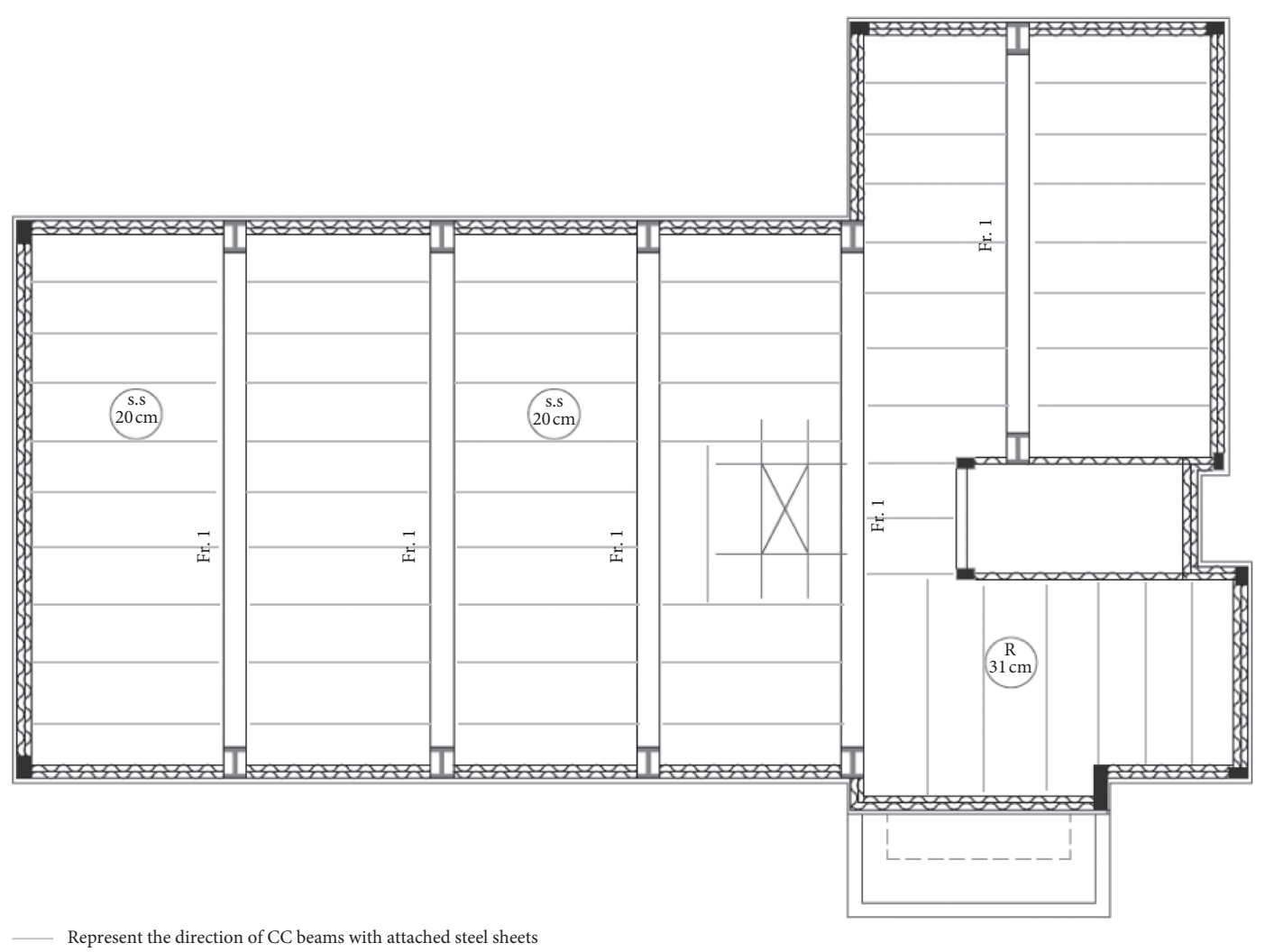

Figure 24: Contour crafting construction.

of action of 3D printing has been illustrated by applying it on Ras Alain Multipurpose Hall. The suggested model of Ras Alain Multipurpose Hall has been generated on Revit Software. Then, the model has been sliced into layers by converting it to stereolithography (STL) file to create the predefined material deposition path which represents the path of the nozzle. Finally, the author has produced a precise image regarding the impact of $3 \mathrm{D}$ printing by comparing conventional construction data related to the required quantities of Ras Alain Multipurpose Hall and the expected data if the same building has been built using $3 \mathrm{D}$ printing. As a result of this comparison for the same construction works for Ras Alain Multipurpose Hall, 3D printing reduces $65 \%$ of concrete cost of conventional construction if it has been applied in Jordan.

Finally, from the author point of view, it is expected that governmental agencies and construction companies would go for $3 \mathrm{D}$ printing procedure to construct their future structures. This technology is poised to revolutionize the construction industry. It can be used for homes, towers, bridges, and emergency shelters during a disaster.

From the results of this research, the author recommends the following:

(1) To apply 3D printing as an alternative to conventional construction according to its ability in reducing the construction time and cost

(2) To apply 3D printing mainly by governmental agencies targeting low-income housing and emergency shelters for refugees
(3) To provide incentives for contractors and engineers to apply $3 \mathrm{D}$ printing

(4) To give lectures about three-dimensional (3D) printing processes for engineering students

(5) To add 3D printing as a course of study to the curriculum

(6) To suggest future works to further assess the potential impact of 3D printing

(7) To extend the research field to include all the construction works by $3 \mathrm{D}$ printing, diversity of materials used by $3 \mathrm{D}$ printing, and additional modeling for multidiscipline design processes

\section{Appendix}

Structural drawings are shown in Figures 23 and 24.

\section{Data Availability}

All data are included within the manuscript.

\section{Conflicts of Interest}

The authors declare that they have no conflicts of interest.

\section{References}

[1] N. Guo and M. C. Leu, "Additive manufacturing: technology, applications and research needs," Frontiers of Mechanical Engineering, vol. 8, no. 3, pp. 215-243, 2013. 
[2] B. Sanz-Izquierdo and E. A. Parker, " 3 D printing technique for fabrication of frequency selective structures for built environment," Electronics Letters, vol. 49, no. 18, pp. 1117-1118, 2013.

[3] F. Ceccanti, E. Dini, X. De Kestelier, V. Colla, and L. Pambaguian, "3D printing technology for a moon outpost exploiting lunar soil," in Proceedings of the 61st International Astronautical Congress, Prague, Czechia, August 2010.

[4] Y. W. D. Tay, B. Panda, S. C. Paul, N. A. N. Mohamed, M. J. Tan, and K. F. Leong, "3d printing trends in building and construction industry: a review," Virtual and Physical Prototyping, vol. 12, no. 3, pp. 261-276, 2017.

[5] F. Bos, R. Wolfs, Z. Ahmed, and T. Salet, "Additive manufacturing of concrete in construction: potentials and challenges of 3D concrete printing," Virtual and Physical Prototyping, vol. 11, no. 3, pp. 209-225, 2016.

[6] J. Pegna, "Exploratory investigation of solid freeform construction," Automation in Construction, vol. 5, no. 5, pp. 427-437, 1997.

[7] S. Lim, R. A. Buswell, T. T. Le, S. A. Austin, A. G. F. Gibb, and T. Thorpe, "In construction-scale additive manufacturing processes," Automation in Construction, vol. 21, no. 1, pp. 262-268.

[8] J. Zhang and B. Khoshnevis, "Optimal machine operation planning for construction by contour crafting," Automation in Construction, vol. 29, pp. 50-67, 2013.

[9] D. Hwang and B. Khoshnevis, "An innovative construction process-contour crafting (CC)," in Proceedings of the 22nd International Symposium on Automation and Robotics in Construction (ISARC 2005), Ferrara, Italy, September 2005.

[10] N. Leach, A. Carlson, B. Khoshnevis, and M. Thangavelu, "Robotic construction by contour crafting: the case of lunar construction," International Journal of Architectural Computing, vol. 10, no. 3, pp. 423-438, 2012.

[11] M. Szilvśi-Nagy and G. Y. Matyasi, "Analysis of STL files," Mathematical and Computer Modelling, vol. 38, no. 7, pp. 945-960, 2003.

[12] S. Lim, T. Le, J. Webster et al., "Fabricating construction components using layered manufacturing technology," in Proceedings of the 2009 Global Innovation in Construction Conference, pp. 512-520, Loughborough, UK, September 2009.

[13] M. Richardson and B. Haylock, "Designer/maker: the rise of additive manufacturing, domestic-scale production and the possible implications for the automotive industry," ComputerAided Design and Applications, vol. PACE, pp. 33-48, 2012.

[14] B. Khoshnevis, "Automated construction by contour craftingrelated robotics and information technologies," Automation in Construction, vol. 13, no. 1, pp. 5-19, 2004.

[15] N. Thakur, "Contour crafting A potential revolution in the construction industry," International Journal of Research in Advent Technology, Special Issue, National Conference, vol. 2, no. 6, pp. 22-26, 2016.

[16] D. M. Roodman, N. K. Lenssen, and J. A. Peterson, A Building Revolution: How Ecology and Health Concerns are Transforming Construction, Worldwatch Institute, Washington, DC, USA, 1995.

[17] T. T. Le, S. A. Austin, S. Lim, R. A. Buswell, A. G. F. Gibb, and T. Thorpe, "Mix design and fresh properties for high-performance printing concrete," Materials and Structures, vol. 45, no. 8, pp. 1221-1232.

[18] V. N. Nerella, "Studying printability of fresh concrete for formwork free concrete on-site 3D printing technology," in
Proceeding of the 25th Conference on Rheology of Building Materials, Regensburg, Germany, March 2016.

[19] G. Van Zijl, S. C. Paul, and M. J. Tan, "Properties of 3d printable concrete," in Proceedings of the 2nd International Conference on Progress in Additive Manufacturing, pp. 421426, Singapore, May 2016.

[20] G. H. A. Ting, Y. W. D. Tay, Y. Qian, and M. J. Tan, "Utilization of recycled glass for 3D concrete printing: rheological and mec hanical properties," Journal of Material Cycles and Waste Management, vol. 21, no. 4, pp. 994-1003, 2019.

[21] M. Hambach and D. Volkmer, "Properties of 3D-printed fiber-reinforced Portland cement paste," Cement and Concrete Composites, vol. 79, pp. 62-70, 2017.

[22] B. Zareiyan and B. Khoshnevis, "Interlayer adhesion and strength of structures in contour crafting-effects of aggregate size, extrusion rate, and layer thickness," Automation in Construction, vol. 81, pp. 112-121, 2017.

[23] Y. W. D. Tay, Y. Qian, and M. J. Tan, "Printability region for 3D concrete printing using slump and slump flow test," Composites Part B: Engineering, vol. 174, Article ID 106968, 2019.

[24] F. Bos, Z. Ahmed, E. Jutinov, and T. Salet, "Experimental exploration of metal cable as reinforcement in 3D printed concrete," Materials, vol. 10, no. 11, p. 1314, 2017.

[25] Y. W. D. Tay, M. Y. Li, and M. J. Tan, "Effect of printing parameters in 3D concrete printing: printing region and support structures," Journal of Materials Processing Technology, vol. 271, pp. 261-270, 2019.

[26] Bari O., Gothic Construction Techniques Inspire ETH Zurich's Lightweight Concrete Floor Slabs, ArchDaily, 2017, https://www. archdaily.com/869192/gothic-construction-techniques-inspireeth-zurichs-lightweight-concrete-floor-slabs/.

[27] D. Hwang, "Experimental study of full scale concrete wall construction using contour crafting," University of Southern California, Los Angeles, CA, USA, Doctoral dissertation, 2005.

[28] D. Asprone, F. Auricchio, C. Menna, and V. Mercuri, "3D printing of reinforced concrete elements: technology and design approach," Construction and Building Materials, vol. 165, pp. 218-231, 2018.

[29] Sevenson B., Shanghai-based WinSun 3D Prints 6-Story Apartment Building and an Incredible Home, 2015.

[30] M. Yossef and A. Chen, "Applicability and limitations of 3D printing for civil structures," in Proceedings of the 2015 Conference on Autonomous and Robotic Construction of Infrastructure, pp. 237-246, Ames, Iowa, June 2015.

[31] Dey P., Site Visit: Office of the Future, Dubai, Unpublished Manuscript, 2016.

[32] Scott C., WinSun Agrees to Provide 100 3D Printers to Saudi Arabian Contractor for 1.5 Million New Homes, 2017, https:// 3dprint.com/168674/winsun-saudi-arabia-3d-printers/.

[33] Valencia N., World's first 3D printed bridge opens in Spain, ArchDaily. (Trans. Valletta, Matthew), 2017, https://www. archdaily.com/804596/worlds-first-3d-printed-bridge-opensin-spain/.

[34] R. Mathur, "3D printing in architecture," International Journal of Innovative Science, Engineering \& Technology, vol. 3, no. 7, pp. 583-591, 2016.

[35] B. Khoshnevis, D. Hwang, K. T. Yao, and Z. Yeh, "Mega-scale fabrication by contour crafting," International Journal of Industrial and Systems Engineering, vol. 1, no. 3, pp. 301-320, 2006.

[36] P. Bosscher, R. L. Williams II, L. S. Bryson, and D. CastroLacouture, "Cable-suspended robotic contour crafting system," Automation in Construction, vol. 17, no. 1, pp. 45-55, 2007. 